Article

\title{
Introduction of Open-Source Engineering Tools for the Structural Modeling of a Multilayer Mountaineering Ski under Operation
}

\author{
Lorenzo Fraccaroli and Franco Concli * \\ Faculty of Science and Technology, Free University of Bolzano/Bozen, Piazza Università 1, 39100 Bolzano, Italy; \\ lorenzo.fraccaroli@unibz.it \\ * Correspondence: franco.concli@unibz.it; Tel.: +39-0471-017748
}

Received: 29 June 2020; Accepted: 28 July 2020; Published: 31 July 2020

\begin{abstract}
Winter sports have significantly developed in the last century. Among others, skiing is a winter-sport branch in which the equipment makes the difference in the performances. While in the beginning of the last century skis were simply made of wood, nowadays the increasing demand of performances and weight reduction has promoted the adoption of composite materials. However, no significant progress has been made in the engineering approach to design such equipment which are very often still designed on the basis of several physical prototypes and trials. This is particularly true in the niche sector of ski mountaineering, where the production batches are significantly smaller with respect to those of alpine skis and at the same time the weight reduction plays a determinant role. In this context, finite elements analysis (FEA) could represent an important tool to shorten the development times and costs leading to a more effective design process. The aim of this research is the development of an accurate virtual model of an existing mountaineering ski, capable of reproducing the behavior of the real component under operation. A preliminary characterization of all the materials used for the different layers of the ski was performed via tensile tests on flat dog-bone-shaped samples in combination with digital image correlation (DIC) techniques. Samples were laser cut from sheets. The tensile tests were performed in the two principal directions for each material. In combination with DIC, these tests allowed us to estimate the four in-plane (XY) elastic properties, namely, the two elastic modules, the shear module, and the Poisson ratio (Ex, Ey, Gxy, vxy). The DIC acquisitions were elaborated with the free software GOM-Correlate. The digital model of the ski was created and simulated in an open-source environment: Code_Aster/Salome-Meca. The reason for using an open-source software is the possibility to parallelize the calculation without restrictions due to licenses and to customize the code according to the specific problem of interest. These aspects underline the potential of open-source software to improve the design process. The results of the simulations were compared with the response of the real ski in a three-point bending and a torsion-bending tests. Differences of $2.5-10 \%$ with respect to the real ski were observed for the different modeling techniques. Moreover, the validated virtual model of the ski was used to study the behavior of the ski when interacting with the snow for different roll angles and loads.
\end{abstract}

Keywords: ski mountaineering; FEM; Code_Aster; DIC; composite materials; Salome-Meca; snow

\section{Introduction}

Ski mountaineering is a niche sector of winter sports in which the equipment, namely the skis, is determinant for the performances of the athletes. Most of the races foresee the climbing of a hill; in this condition having a light ski is fundamental. Moreover, during the downhills, the lightweight is not as important as the stiffness of the ski. Finding the best compromise between these 2 main properties means 
designing a good ski. However, the optimization process requires several attempts and, considering that the current design approaches of ski-mountaineering (skimo or skialp) are characterized by a relevant testing activity, the whole development of a new model could be very expensive and time consuming. A preliminary screening of the multifarious designs is made by simplified laboratory tests, such as three-point-bending or torsional tests. Only the most promising prototypes are tested by skilled professional skiers, like mountain guides, or athletes that can give a more accurate evaluation of the properties of the ski in real conditions which characterize their practical use. This trial and error approach has significant economical disadvantages and requires long times for assembling and testing all the ski variants. Having the possibility to reduce the number of physical prototypes with a virtual preliminary screening could represent a significant improvement of the whole design and manufacturing process.

Finite element analysis (FEA) is already used for the development and design phases of alpine downhill skis [1-4]. In literature, several works in which the mechanical behavior of alpine or carving skis is analyzed are present [5-7]. However, the adoption of these modeling techniques for the development of mountaineering skis seem to be not yet widespread. It must be highlighted that for ski-mountaineering the necessity to find a balance between performances and lightweight design represents an additional issue which complicates the design [8]. The aim of the present study is to develop a reliable numerical model of an existing mountaineering ski. The model is based on the geometrical data of the ski and the results of material characterization tests of the different layers of the ski obtained combining tensile tests on flat dog-bone-shaped samples with digital image correlation (DIC) measurements. The dog-bone-shaped specimens were produced by laser cutting. Each material was tested in two different directions. For the materials for which it was possible, the tensile test was repeated twice. Digital image correlation [9-16] combined with the Campbell [17] hypothesis allowed the estimation of the four in-plane elastic properties.

Moreover, a real prototype (ski available on the market) was also tested in three-point-bending and bending-torsional tests. Simulations of these two conditions were performed with different levels of simplifications. The numerical results were compared with those obtained from three-point bending and torsion-bending tests on the real ski [18].

Once the numerical model of the ski was validated, its behavior in different working conditions was studied. In particular, the ski-snow interaction was simulated. The snow was modeled according to Lintzèn [19]. Different roll angles and loads were simulated to better understand the behavior of the ski under operation.

\section{Materials and Methods}

\subsection{Ski Overview}

Modern skis are composed of a multilayer composite structure, with a wood or honeycomb softcore that guarantees good flexibility and low weight. This core is wrapped with different layers. These are typically carbon-, basalt- and glass-fiber-reinforced materials. Resistance and stiffness of the ski are mainly determined by the material of these wrapping layers. The upper and the bottom layers do not have structural purposes. The first one is just required for a better appearance of the ski while the latter is chosen in order to reduce the friction between ski and snow. To obtain a high-performing ski, it is important to find a good balance between weight, resistance, and stiffness. Solutions with an increased number of layers ensure the most performing designs. However, increasing the number of layers and materials also implies the need for producing and testing many more prototypes. Without FE simulations, this is very difficult and time consuming, and the experience of the manufacturer represents the only available tool for speeding up the development. 


\subsection{Methods}

To give a general validity to the adopted approach, the mechanical properties of the different materials were obtained with dedicated tensile tests combined with DIC techniques. These allow the characterization of the 4 in-plane elastic properties of each material used in the ski successively tested. The materials used in the ski manufacturing are composited themselves. They have two major constituents, fibers and matrix. Fibers ensure the resistance and stiffness, while matrix plays the role of keeping the fibers together and protecting them from external agents. The theory of orthotropic laminas and laminated structures could be used for describing these materials. The assumption of having (for each material) just one principal direction was made. Orthotropic materials can be described in the space with 9 independent elastic parameters (for a completely non-isotropic material the constants are 21). For a lamina of small thickness and with longitudinal continuous fibers, the elastic behavior can be described with 4 elastic constants only: The 2 in-plane elastic modules, the in-plane shear module, and one of the two in-plane Poisson ratios. The 2 elastic modules can be obtained directly from unidirectional tensile tests while the Poisson's ratio can be extrapolated from digital image correlation (DIC) measurements. The shear module was evaluated by means of the approximated Campbell formula [17].

The tested materials are identified with a code number. Specifically, 9, 24, 139, 207, 290, 135, 31, 86, and 217.

Tensile tests were performed on the STEPLab UD04 (Figure 1) testing machine available in the labs of the Free University of Bolzano/Bozen. It is capable to apply static forces up to $4.5 \mathrm{kN}$. Each test was performed with a crosshead speed $0.1 \mathrm{~mm} / \mathrm{min}$.
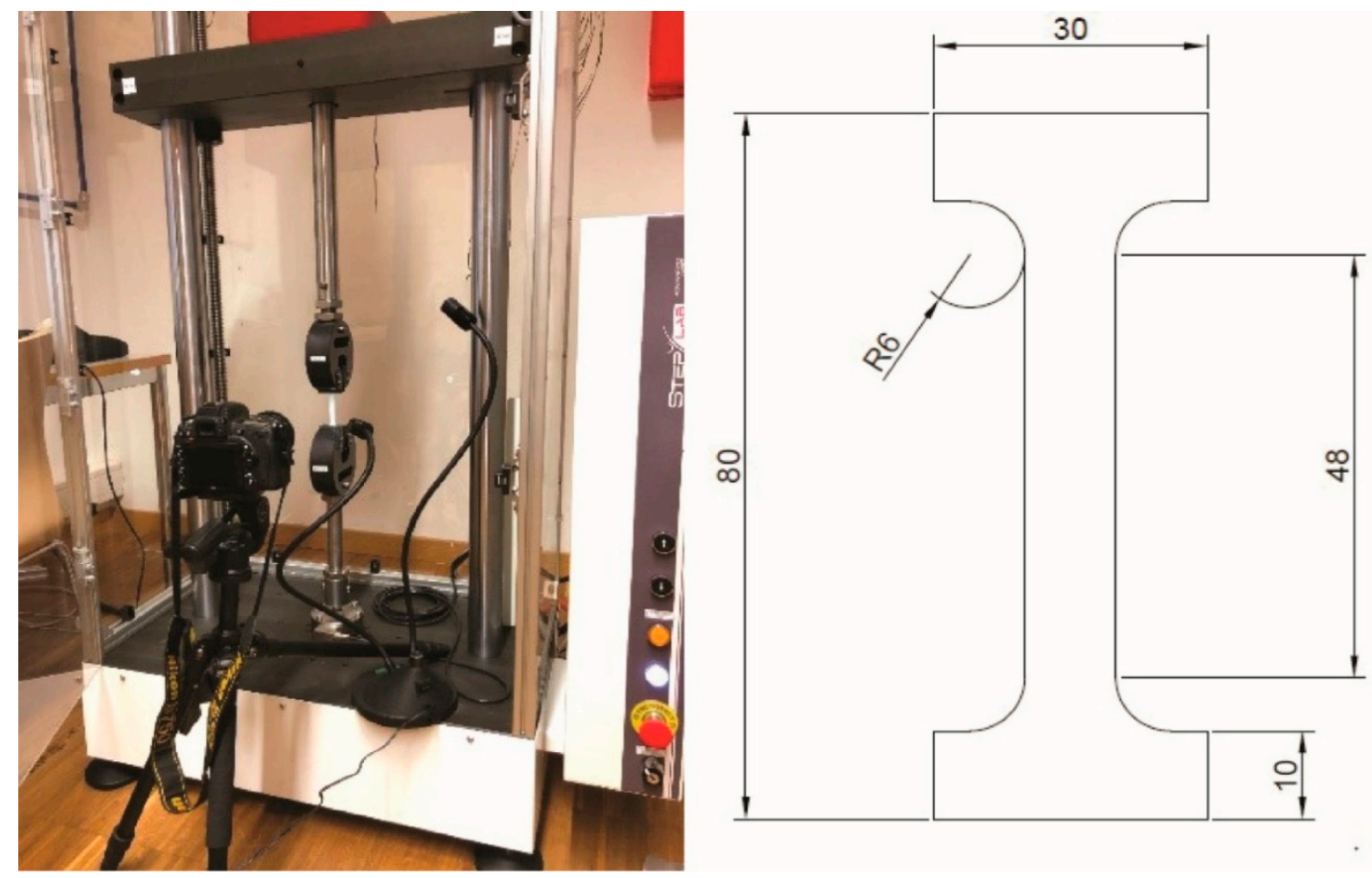

Figure 1. STEPLab UD04 tensile machine and testing setup; (right) dog-bone sample geometry and dimensions.

While the Young's modules can be directly derived from the monoaxial tests, the estimation of the Poisson's ratio requires the calculation of the strains in 2 perpendicular directions (Equation (1)).

$$
v_{x y}=-\frac{\varepsilon_{y}}{\varepsilon_{x}} ; v_{y x}=-\frac{\varepsilon_{x}}{\varepsilon_{y}}
$$


Digital image correlation (DIC) was used for this purpose. A reflex Nikon D750 camera with a 24-85 zoom, 32 MPixel resolution, and a stabilizer was placed perpendicularly to the specimen surfaces. It acquired pictures of the sample at each $0.5 \mathrm{~s}$. External light sources were used for a better illumination of the specimen's surface.

Two-dimensional digital image correlation is an advanced optical measurement technique allowing displacement and strain fields on a planar surface to be reconstructed.

Firstly, a characteristic black and white "speckle" pattern was created on the specimen surface. Pictures were acquired at a fixed rate for the entire tensile test. The first picture acquired (undeformed sample) was used as reference. Cross correlation operations allowed the recognition of facets (subsets of the specimen's surface) across all the time steps (corresponding to different images and deformations) (Figure 2). Once all subsets were recognized for each timestep, the displacement field and successively the strain field of the tested component could be reconstructed. The software used was GOM-Correlate [20].
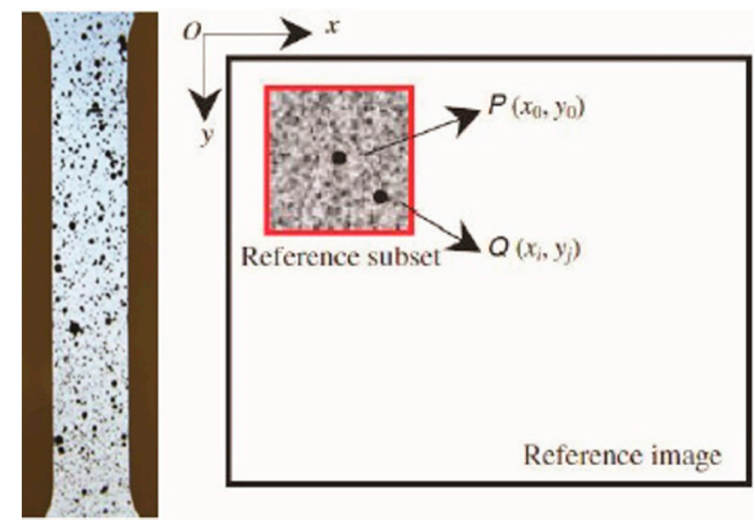

(a)

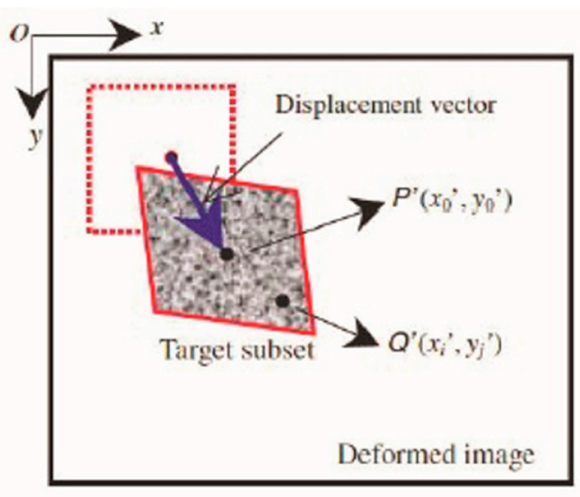

(b)

Figure 2. Digital image correlation (DIC); (a) surface pattern; (b) cross correlation.

Knowing the strains in 2 independent directions allowed the calculation of the Poisson's ratio according to Equation (1). The shear module could be finally obtained using the Campbell equation (Equation (2)).

$$
\frac{1}{G_{x y}}=\frac{\left(1+v_{x y}\right)}{E_{x}}+\frac{\left(1+v_{y x}\right)}{E_{y}}
$$

\subsection{SKI}

In this research the open-source software Code_Aster/Salome-Meca was used. Three-pointbending and bending-torsional tests were numerically reproduced. Figure 3 shows the schematic representation of the loaded ski.

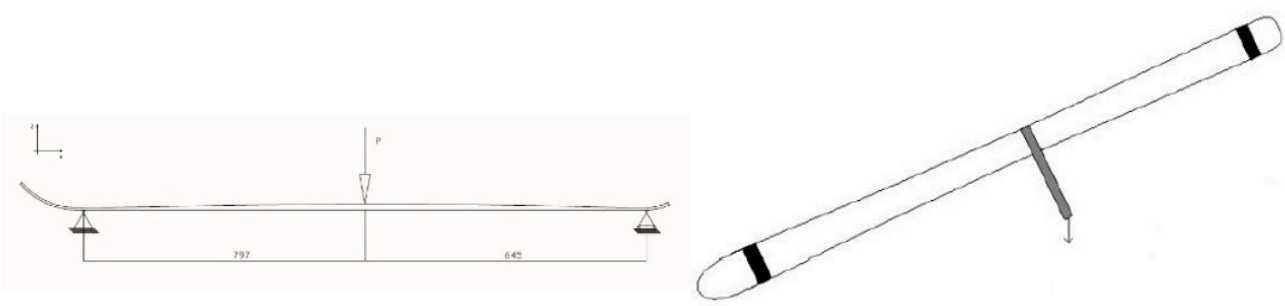

Figure 3. Schematic representation of the three-point bending and torsion-bending tests-reference case for the FE simulations. 


\subsubsection{Shell Model}

Figure 3 shows the schematic layout of the three-point-bending test. In the virtual model, just half of the structure was simulated, taking advantage of the symmetry. Moreover, the tail and the tip of the ski were not modeled to simulate only the part of the component that falls within supports. Due to their very low-resistant contribution and their very small section, the steel edges were considered negligible and were not modeled as well. A multilayered shell approach was used. The ski was divided into 145 sectors to achieve a good approximation of the curvature of the ski-this ensured a good reproduction of the effective thicknesses along the whole ski. The final grid consisted of about $22 \mathrm{k}$ quadrangular elements. Figure 4 shows the 2D model of the ski.

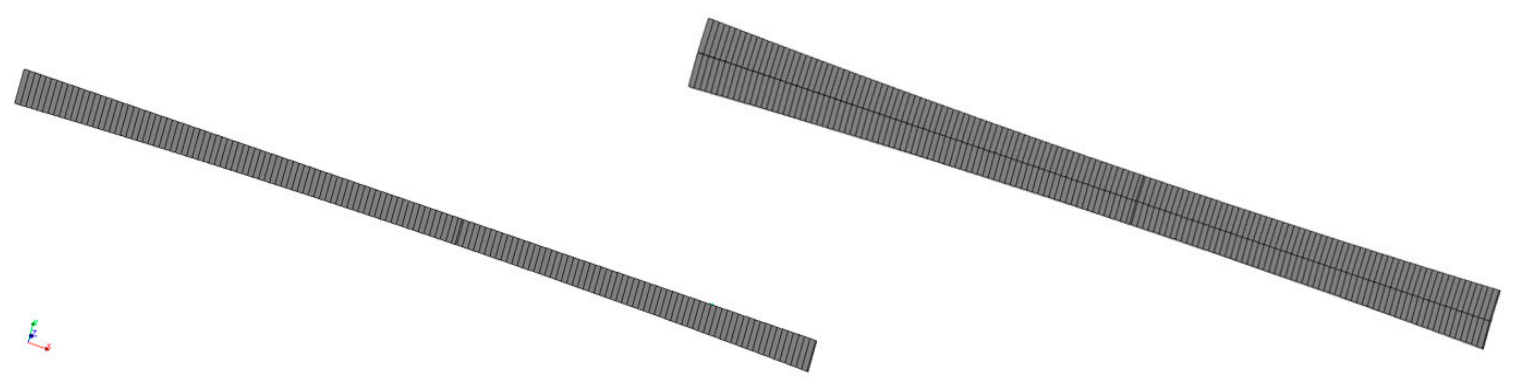

Figure 4. Shell models used for the three-point-bending (left) and torsion-bending (right) simulations.

The torsion-bending test was simulated numerically in a similar way, without exploiting the $\mathrm{z}-\mathrm{x}$ plane-symmetry.

\subsubsection{Solid Model}

The same geometrical simplifications of the shell model were also used for the 3D simulations (symmetry for the three-point-bending model and cutting of tail and tip for both models). Moreover, additional assumptions have been made in order to obtain all the 9 constants necessary for the proper description of the materials in the space. According to [21], materials with unidirectional long fibers have the same elastic module in each radial direction (perpendicular to the reinforcing fibers). The characterization tests were performed on thin laminates and it was not possible to characterize the remaining out of plane properties. The shear module $G$ and the Poisson's ratio $v$ founded in the $\mathrm{xy}$ plane were used also for the other 2 directions ( $\mathrm{zx}$ and $\mathrm{yz}$ ). While in the 3D modeling approach some additional hypothesis were introduced for the material properties, from a geometrical point of view the 3D model (Figures 5 and 6) better reproduced the real shape of the ski, as it also included the lateral protective layer that was neglected in the shell approach.

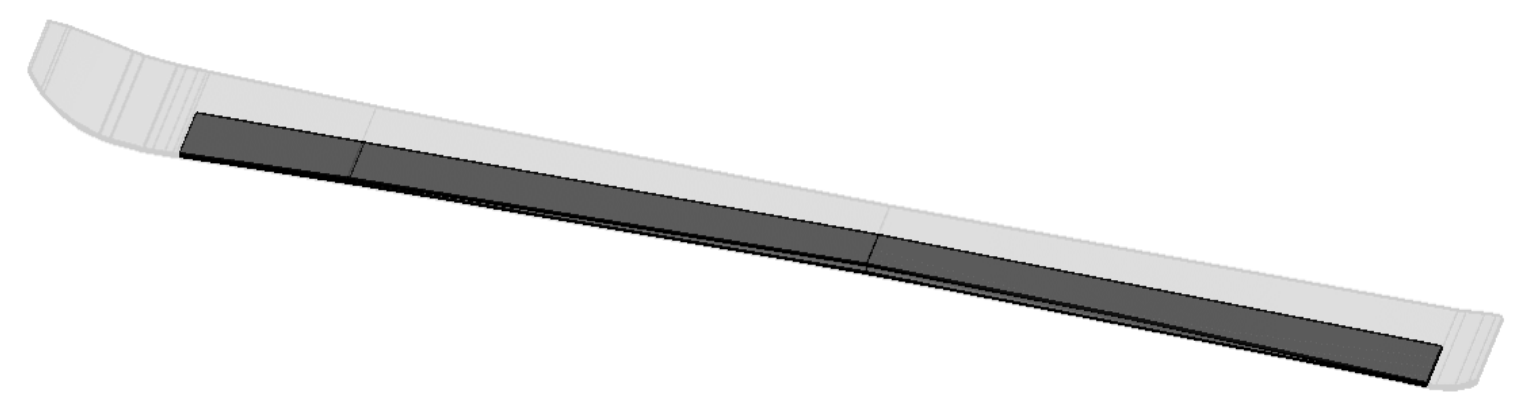

Figure 5. Isometric view of the solid model used for the three-point-bending test. 

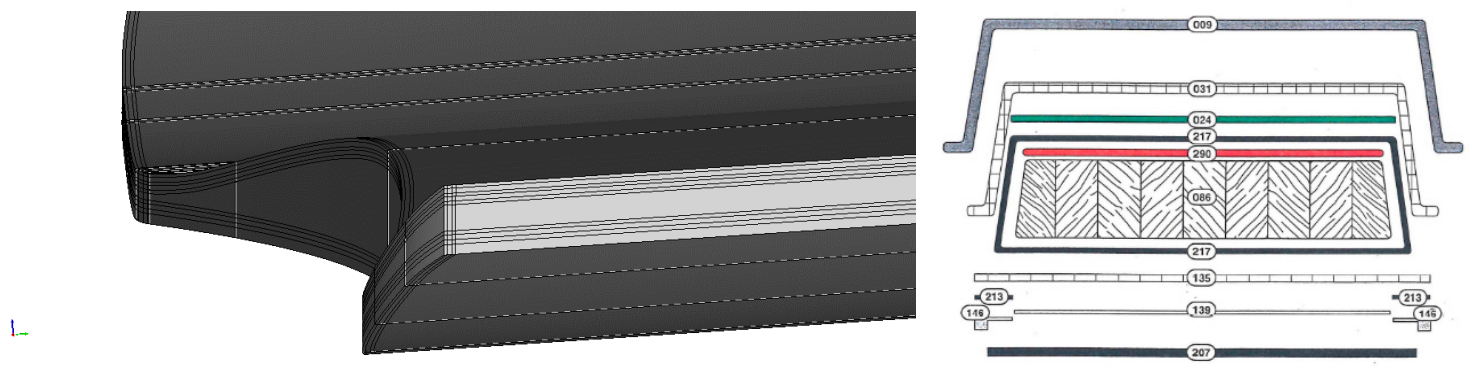

Figure 6. Different layers of the solid model.

The mesh was made of quadratic hexahedrons only. A total number of about $500 \mathrm{k}$ cells was used for the symmetric model reproducing the three-point-bending configuration. The bending-torsional model was made of about $1 \mathrm{M}$ cells.

\section{Experimental Results and Validation of the Virtual Model of the Ski}

The results of the monoaxial tests are presented in Figures 7-13.
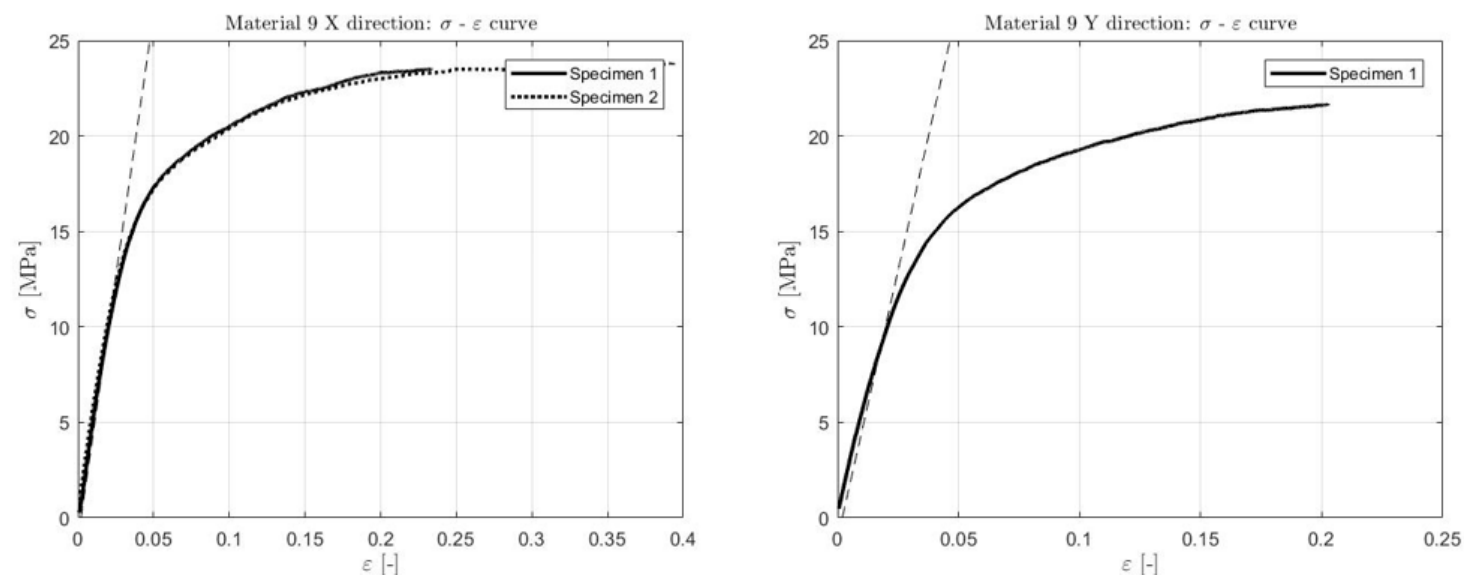

Figure 7. Material 9 tensile tests.
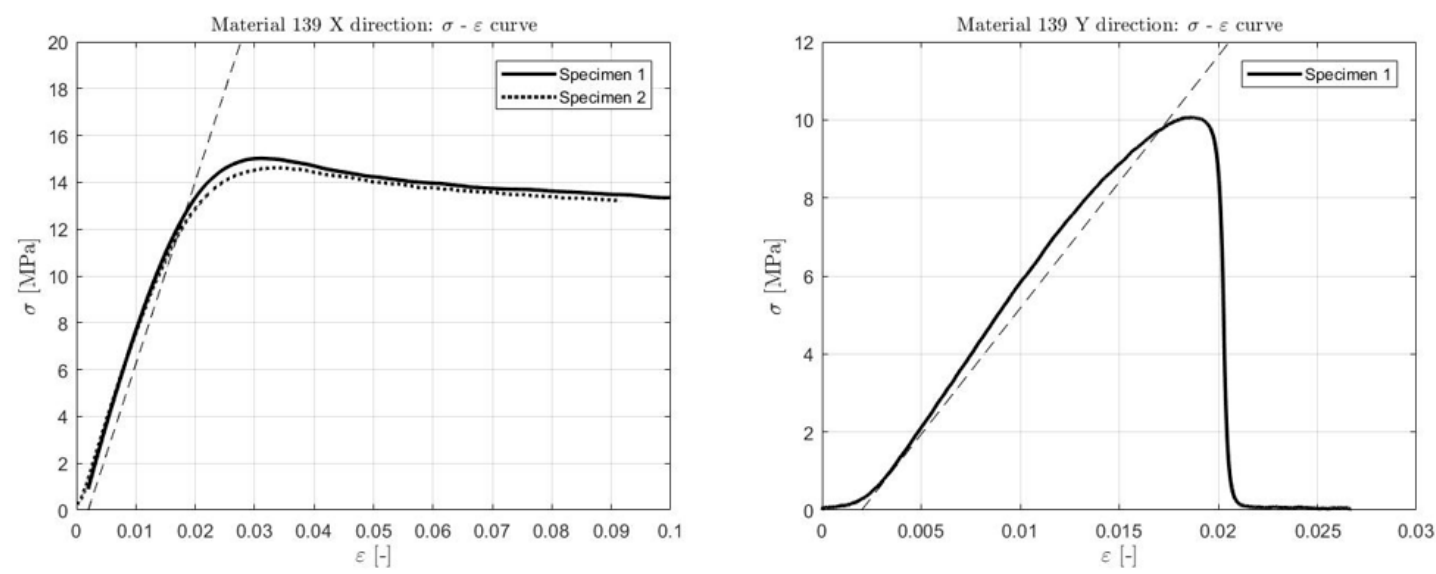

Figure 8. Material 139 tensile tests. 

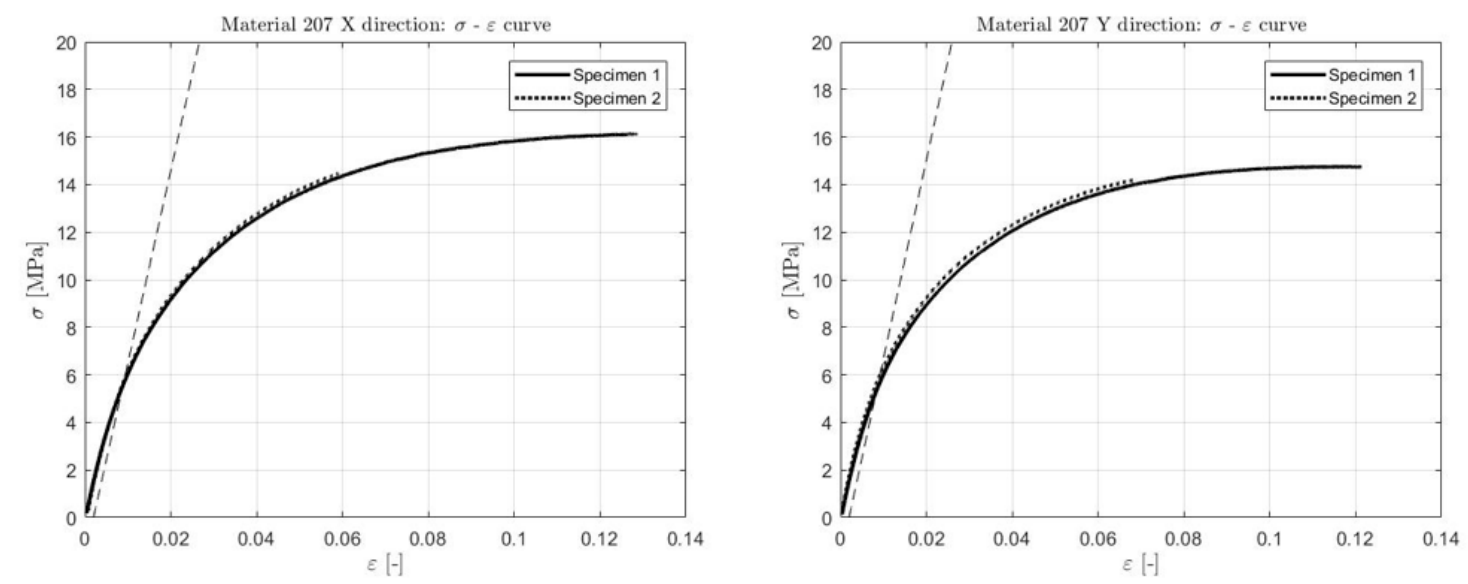

Figure 9. Material 207 tensile tests.
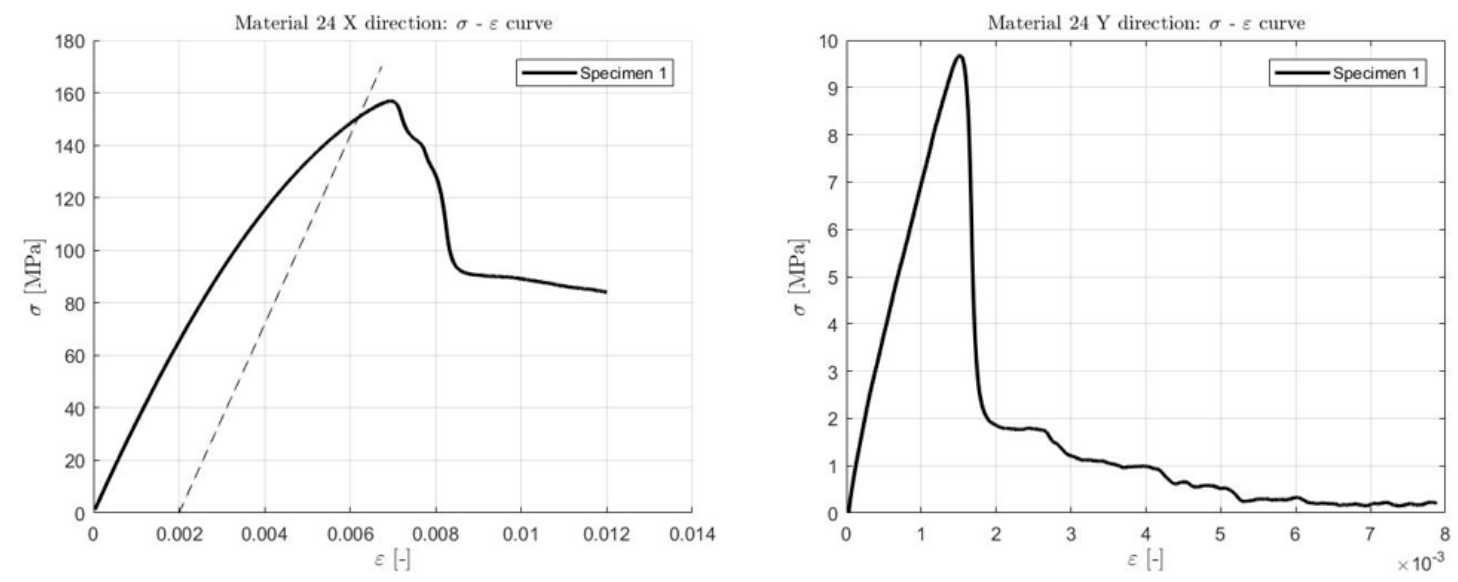

Figure 10. Material 24 tensile tests.
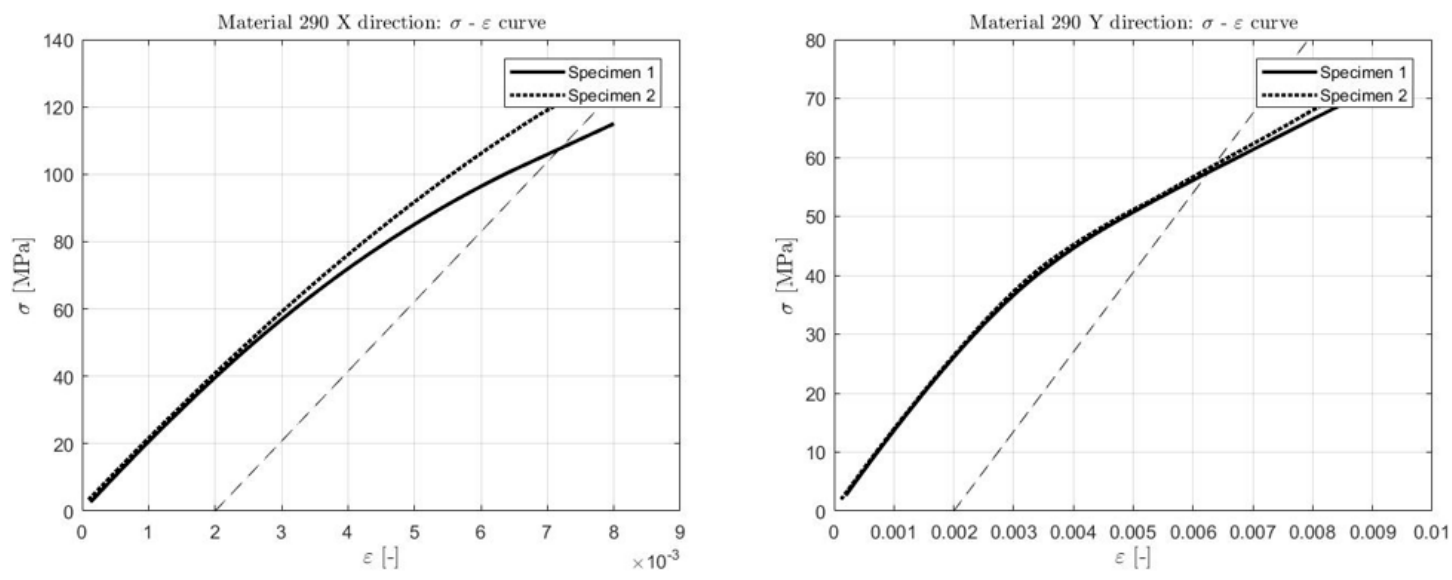

Figure 11. Material 290 tensile tests. 

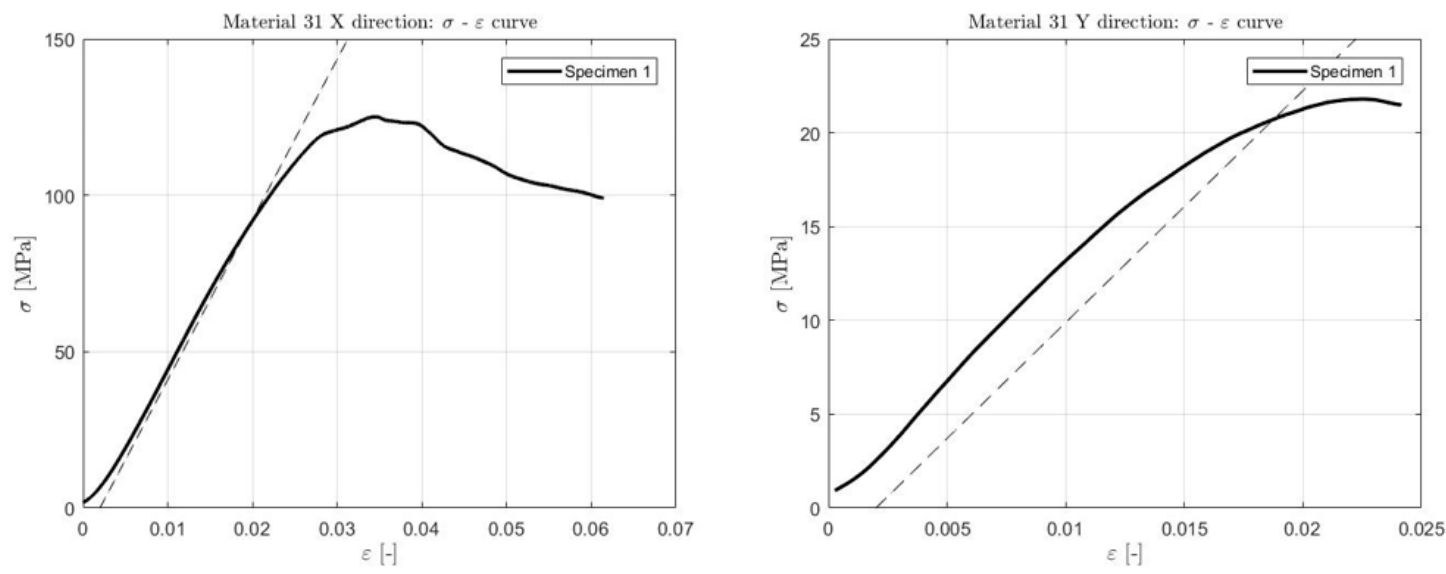

Figure 12. Material 31 tensile tests.
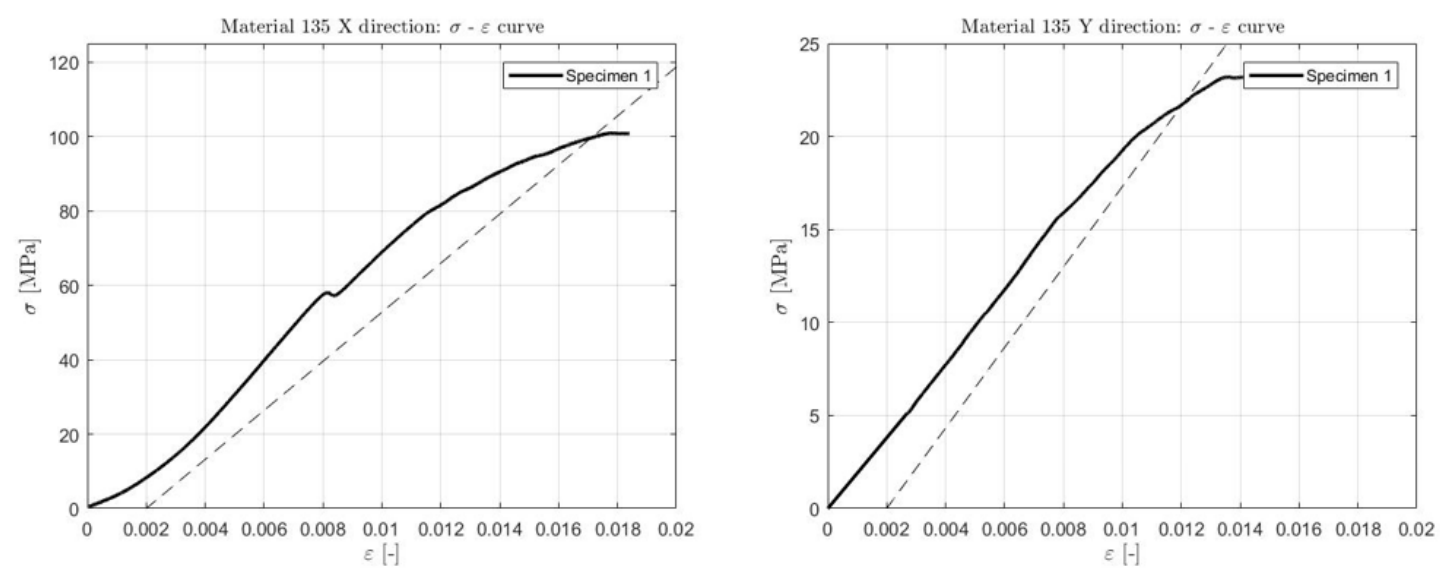

Figure 13. Material 135 tensile tests.

Table 1 reports the in-plane parameters for each material.

Table 1. Material elastic properties.

\begin{tabular}{cccccccccc}
\hline & \multicolumn{10}{c}{ Material } \\
\cline { 2 - 11 } & $\mathbf{9}$ & $\mathbf{2 4}$ & $\mathbf{1 3 9}$ & $\mathbf{2 0 7}$ & $\mathbf{2 9 0}$ & $\mathbf{1 3 5}$ & $\mathbf{3 1}$ & $\mathbf{8 6}$ & $\mathbf{2 1 7}$ \\
\hline $\mathbf{E}_{\mathbf{x}}[\mathbf{M P a}]$ & 550 & 35,000 & 800 & 850 & 20,000 & 4000 & 2000 & 13,700 & 35,000 \\
$\mathbf{E}_{\mathbf{y}}[\mathbf{M P a}]$ & 567 & 8700 & 750 & 897 & 13,700 & 569 & 127 & 420 & 12,436 \\
$\boldsymbol{v}_{\mathbf{x y}}[-]$ & 0.45 & 0.23 & 0.45 & 0.42 & 0.18 & 0.39 & 0.39 & 0.40 & 0.56 \\
$\boldsymbol{v}_{\mathbf{y x}}[-]$ & 0.43 & 0.35 & 0.38 & 0.30 & 0.12 & 0.39 & 0.39 & 0.40 & 0.48 \\
$\mathbf{G}_{\mathbf{x y}}[\mathbf{M P a}]$ & 776 & 35,010 & 1097 & 1291 & 29,125 & 3009 & 1184 & 10,086 & 25,327 \\
$\boldsymbol{\sigma}_{\mathbf{x}}[\mathbf{M P a}]$ & 11 & 152 & 10 & 6 & 110 & 98 & 87 & - & - \\
$\boldsymbol{\sigma}_{\mathbf{y}}[\mathbf{M P a}]$ & 10 & 9 & 13 & 6 & 57 & 22 & 21 & - & - \\
Thickness $[\mathbf{m m}]$ & 0.35 & 0.35 & 0.50 & 1.10 & 1.20 & 0.55 & 0.55 & $0-5.45$ & 0.5 \\
\hline
\end{tabular}

* The sub-indexes $x$ and $y$ refer to the longitudinal and axial ski direction, respectively.

Table 2 reports the maximum displacement in the midpoint of the ski when bended under a load of $120 \mathrm{~N}$ in the three-point-bending tests. Measured values were compared with those obtained from the two different FEM analyses (with shell and solid elements). 
Table 2. Comparison of the maximum deflection of the ski in the three-point bending test: Finite element analysis (FEM) vs. experiments.

\begin{tabular}{cccc}
\hline Model & Displacement $[\mathbf{m m}]$ & Simulation Time * $[\mathrm{min}]$ & Error [\%] \\
\hline Experimental & 40 & & \\
Shell & 41 & 35 & $2.5 \%$ \\
Solid & 44 & 60 & $10.0 \%$ \\
\hline
\end{tabular}

Table 3 reports the results of the torsion-bending tests $(40 \mathrm{~N} @ 0.45 \mathrm{~m})$ and the related numerical predictions.

Table 3. Comparison of the maximum deflection of the ski in the torsion-bending test: FEM vs. experiments.

\begin{tabular}{|c|c|c|c|}
\hline Model & Rotation Angle $\left[^{\circ}\right]$ & Simulation Time ${ }^{*}[\mathrm{~min}]$ & Error [\%] \\
\hline Experimental & 4.44 & & \\
\hline Shell & 4.61 & 35 & $3.0 \%$ \\
\hline Solid & 4.86 & 60 & $9.5 \%$ \\
\hline
\end{tabular}

* on a 9.6 GFLOPS workstation.

Figure 14 shows the normal stresses in the thickness of the ski (on the symmetry plane and the position where the load was applied -0 corresponds to the bottom part) during the three-point-bending test. Figure 15 refers to the bending-torsion test.
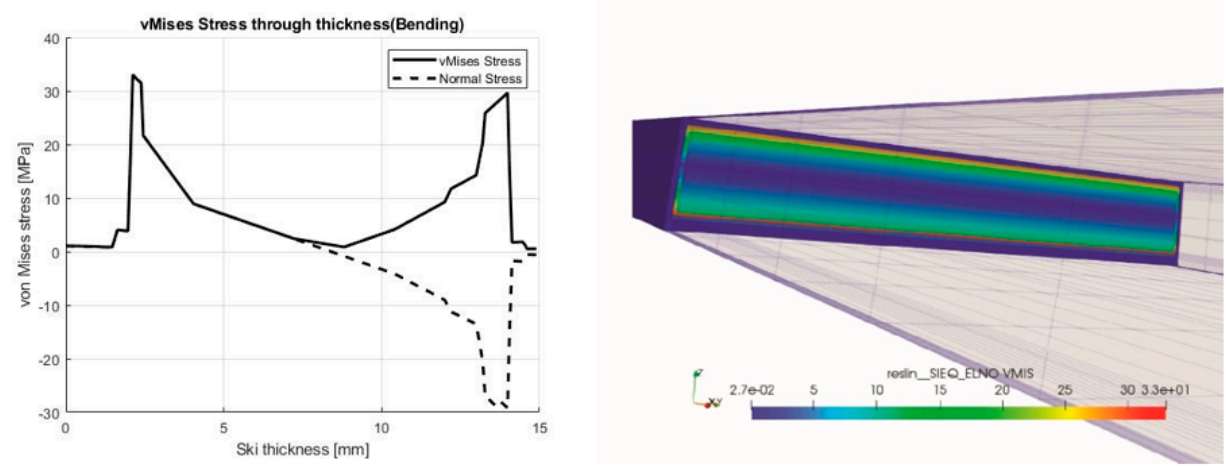

Figure 14. Solid model results—-three-point-bending test (normal and Von Mises stresses in the section).
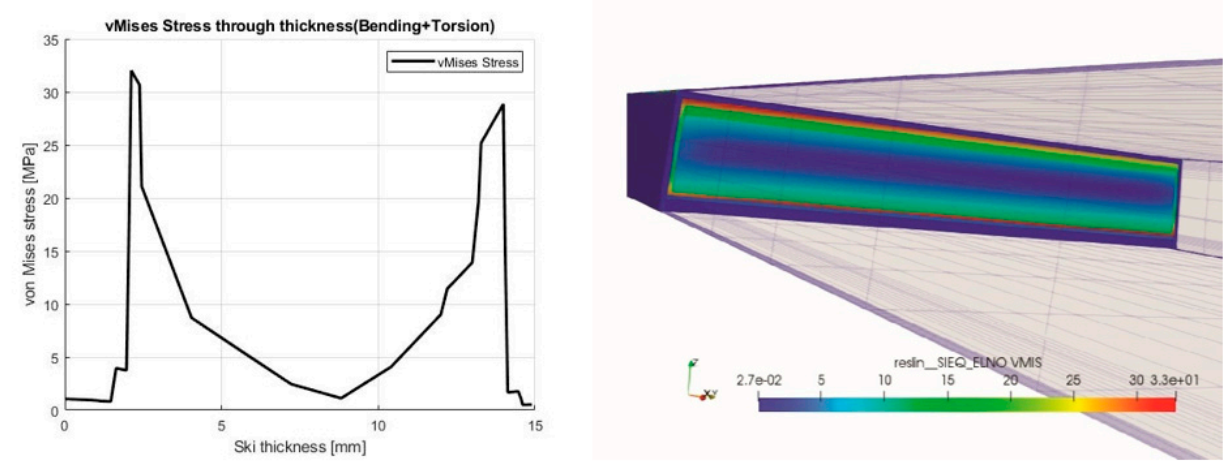

Figure 15. Solid model results—-torsion-bending test (normal and Von Mises stresses in the section).

Both tests were repeated increasing the load up from the first yielding. The most loaded layer was the $\mathrm{n} .217$, in which the stress reached a value of about $32 \mathrm{MPa}$ both in the three-point-bending and in the bending-torsion test. 
Nevertheless, even if the first yielding took place for a relative low force, these specific loading conditions (very useful to validate the model because easily reproducible with lab tests) were not representative of the real loading condition of a ski during operation. The contact with the snow, in fact, promoted a more uniform load transfer from the ski to the ground and, therefore, a significantly less critical stress state for the same applied loads. For this reason, the numerical model was improved including the interaction with the snow to study the behavior of the ski during operation. Friction was neglected.

\section{Behavior of the Ski during a Carving Turn}

To study the behavior of the ski during a downhill turn, the ski-snow interaction had to be modeled. For doing this, the Lintzèn [19] model of snow was used. It is based on experimental compression tests on big frozen snow cylindrical samples. Lintzèn came up with a relation that described the snow as a piece-wise linear function as shown in Figure 16. The snow was characterized by an initial linear behavior in which the elastic constant assumed a value that varied between $\mathrm{E}_{\tan }=115$ (old snow) and $\mathrm{E}_{\tan }=160 \mathrm{MPa}$ (artificial snow). For higher strains, the behavior could be still described with a linear relation in which elastic module assumed a value between $E_{\text {res }}=9$ and $\mathrm{E}_{\text {res }}=35 \mathrm{MPa}$.

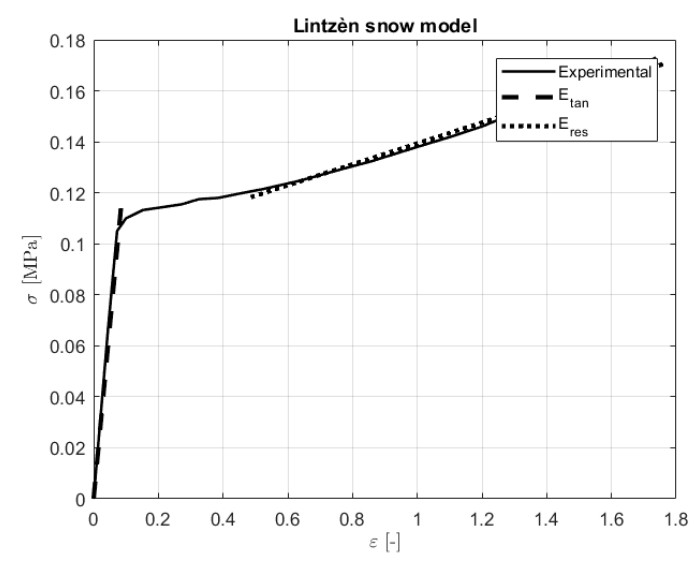

Figure 16. Snow model according to Lintzèn—adapted from [19].

The previously developed and validated solid model of the ski was improved by adding the interaction with the snow. The ski was tested for different roll angles and loads. The roll angle describes the rotation of the ski along its longitudinal axis with respect to the ground. Table 4 shows the studied combinations.

Table 4. Roll angles and forces applied.

\begin{tabular}{cccc}
\hline Roll Angle $\left[{ }^{\circ}{ }\right]$ & Force Applied $[\mathbf{k g}]$ & Maximum Deflection [mm] & Maximum Snow Penetration [mm] \\
\hline 10 & 50 & 2.85 & 8.26 \\
10 & 100 & 2.88 & 8.29 \\
10 & 200 & 2.94 & 8.35 \\
30 & 50 & 9.00 & 12.82 \\
30 & 100 & 9.07 & 12.89 \\
30 & 200 & 9.15 & 12.97 \\
45 & 50 & 15.01 & 17.01 \\
45 & 100 & 15.15 & 17.17 \\
45 & 200 & 15.30 & 17.32 \\
60 & 50 & 29.02 & 22.59 \\
60 & 100 & 29.31 & 22.88 \\
60 & 200 & 29.61 & 22.18
\end{tabular}

* The roll angle is defined as the angle at which an object must be rotated about its longitudinal axis to bring its sagittal- into a horizontal-plane. 
Simulations were performed with a non-linear solver using a large strain formulation. The snow was modeled using a von Mises elastoplastic law with linear isotropic hardening. The contact was modeled as discrete. The models of contact and friction were drawn up from already discretized quantities, i.e., displacements and nodal forces. The problem of contact/friction was solved by uncoupling it from the problem of the equilibrium of structure.

Figure 17 shows the deformed ski under load. Figures 18 and 19 show the deformed shape of the ski along the symmetry plane for several levels of load and different roll angles. These results were fundamental to understand the downhill behavior of the ski: The combination of its carving, roll angle, and load applied determined the turning angle (assuming a conductive turn was done, i.e., without sliding between the ski and the snow). The actual stiffness of the ski was fundamental in this regard: A stiffer ski would require a much higher load to ensure the same turning angle (at equal carving and roll angle). Therefore, skis having the same geometry should have different stiffnesses according to the weight of the athlete. Numerical simulations could be an effective tool for designing the perfect ski.

Figure 20 shows the relation between the roll angle and the turning radius. The relation is well described by a decreasing power function.

$$
r_{\text {turn }}=1529.5 \cdot \vartheta_{\text {roll }}^{-1.129}
$$

The applied load seemed to have a moderate effect on the ski deflection compared to the roll angle. With a roll angle of $45^{\circ}$, in the hypothesis of the conduction turn, the ski showed a turning radius of about $22 \mathrm{~m}$. The geometrical rounding radius of the ski was $40 \mathrm{~m}$. For lower roll angles $\left(30^{\circ}\right.$ and $\left.10^{\circ}\right)$, the rounding radius results equaled to 34 and $111 \mathrm{~m}$, respectively. At a roll angle of $60^{\circ}$, the turning radius decreased to $14 \mathrm{~m}$.

Figure 21 shows the von Mises stress in the cross-section of the ski for different roll angles and loads. Differently from what was observed during the three-point-bending and torsion-bending tests, the interaction with the snow prevented big deformations and the maximum stress level results were far below the yielding for each layer.

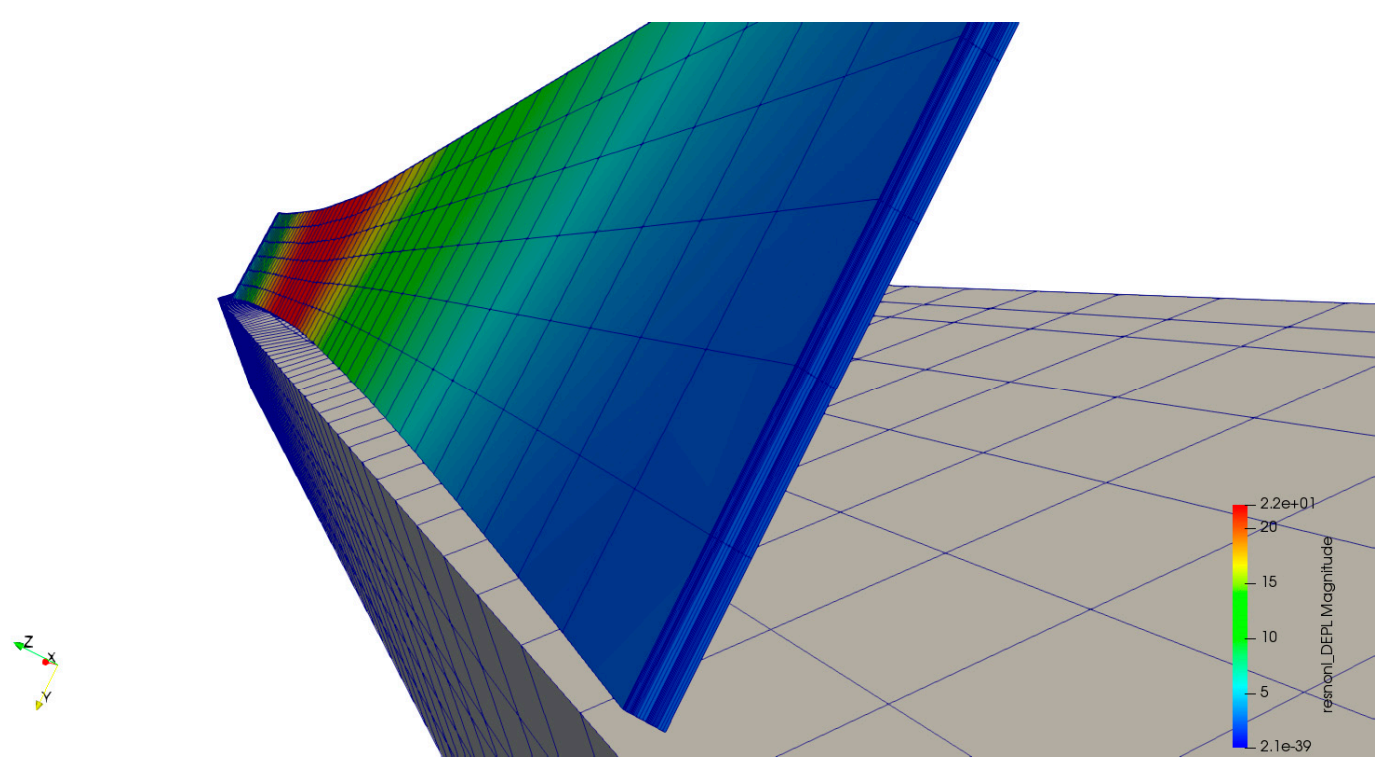

Figure 17. Ski in contact with the snow: Roll angle $45^{\circ}$, load $200 \mathrm{~kg}$. 

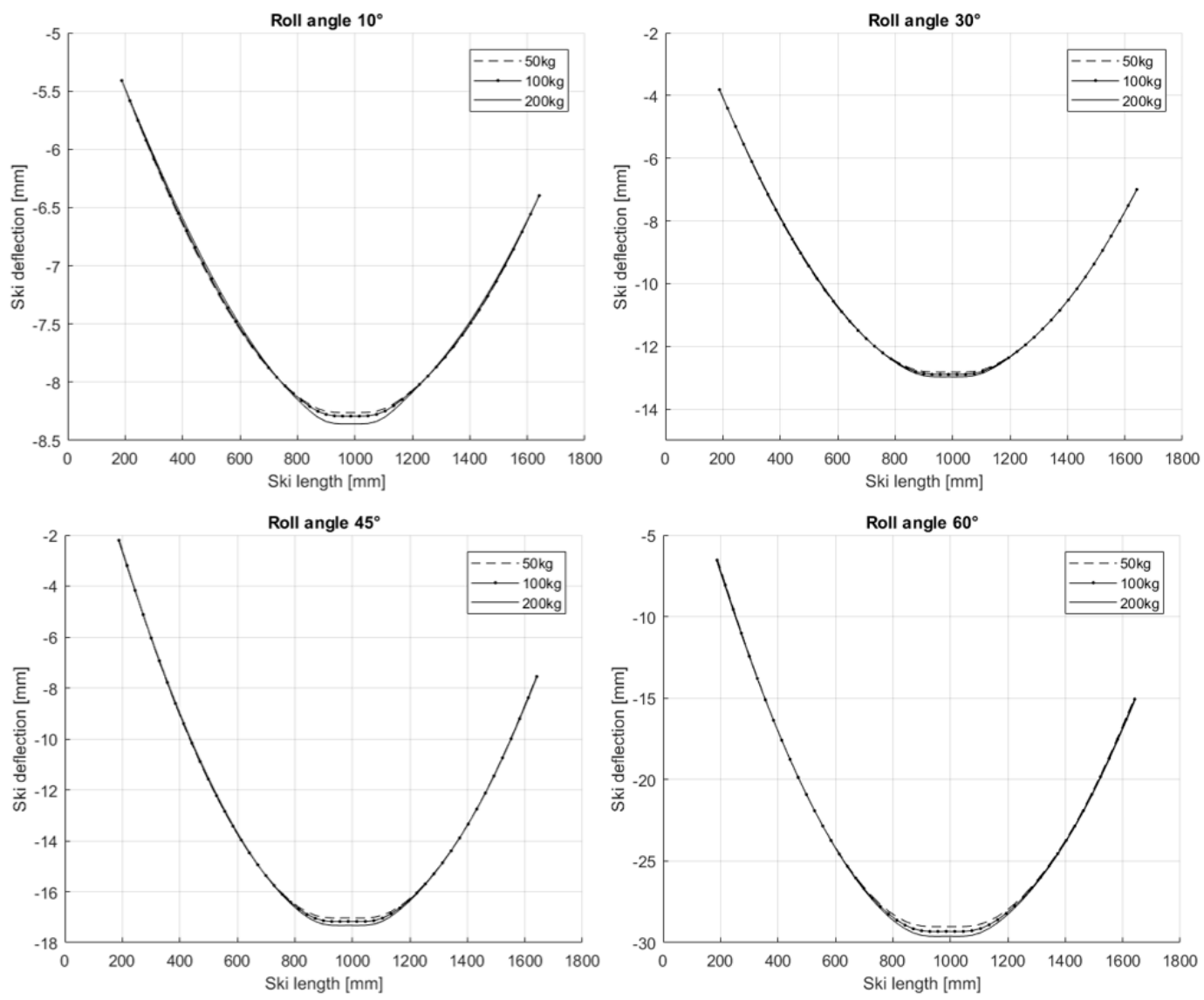

Figure 18. Deflection of the ski for different roll angles and loads.

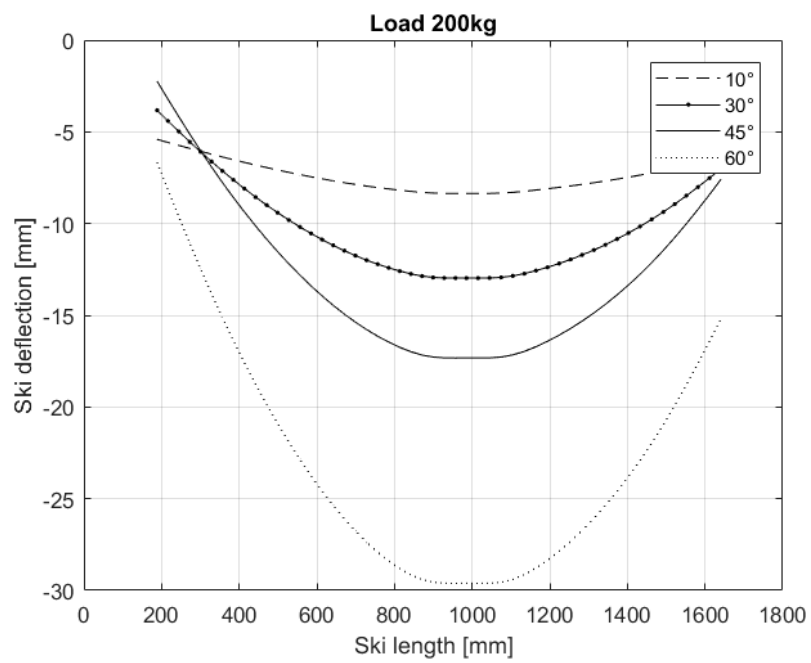

Figure 19. Deflection of the ski for different roll angles and $200 \mathrm{~kg}$. 


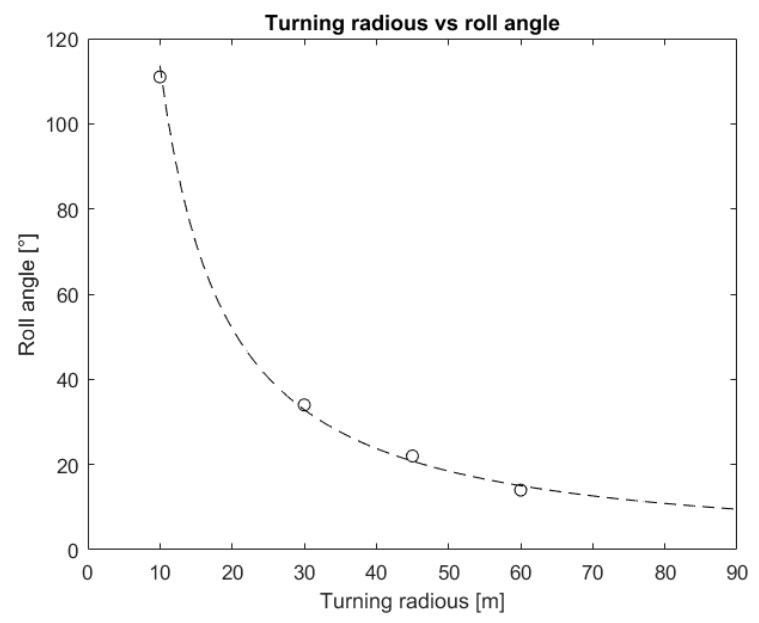

Figure 20. Turning radius vs. roll angle.
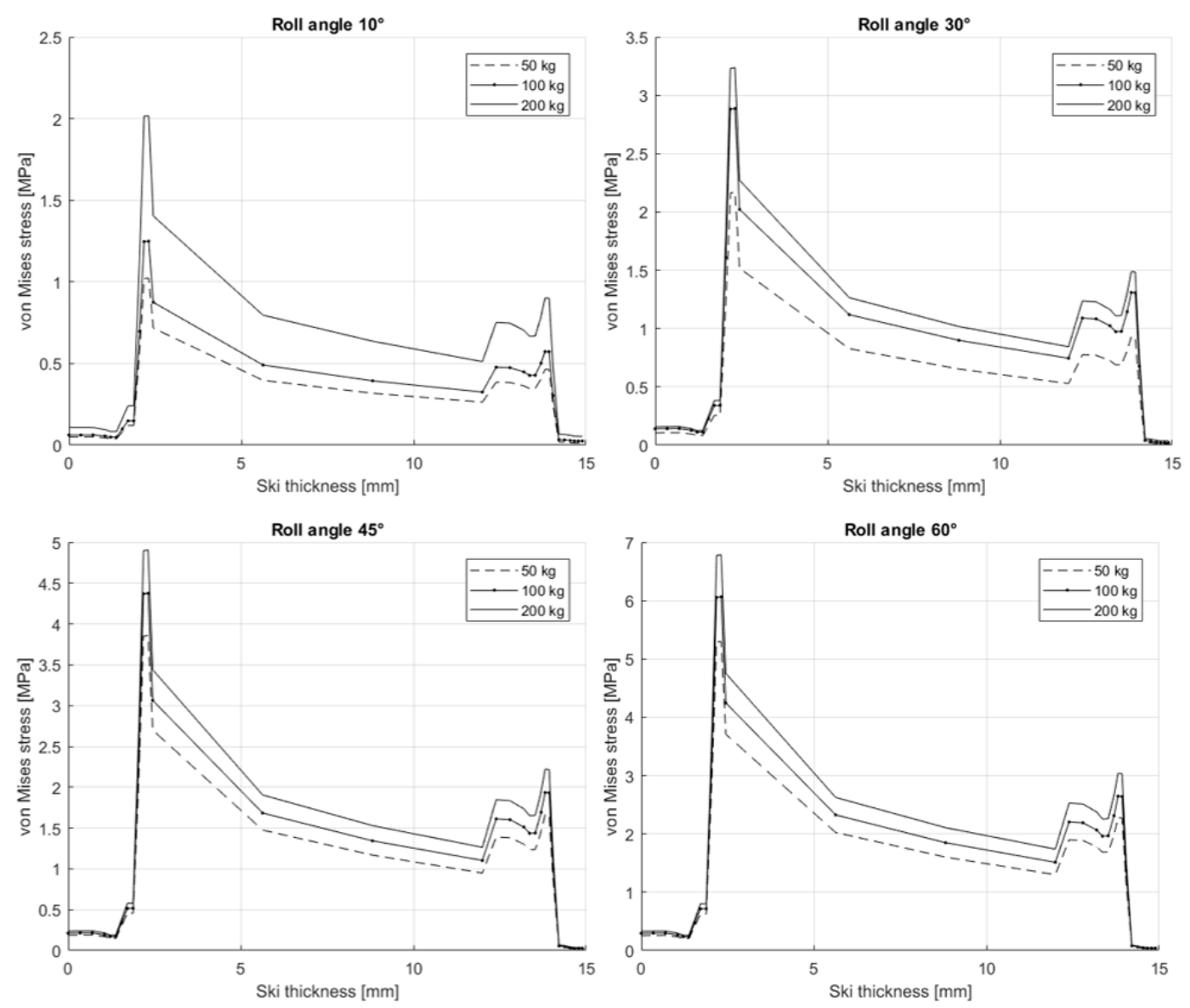

Figure 21. Von Mises stress in the cross-section of the ski for different roll angles and loads.

\section{Discussion}

For its nature, the ski works in the elastic field only. Plastic deformations should be avoided. Therefore, during the experimental measurements, the constitutive law was characterized up to the yielding only. Most of the tested materials showed a good repeatability in the results. In some cases, due to low availability of materials, only one specimen was tested. Repetitions were possible for material 207 (both directions), 290 (both directions), 139 (X direction), and 9 (X direction). The discrepancies between repetition were very small, confirming the correct configuration of the testing setup and 
adequacy of the measuring devices. Materials \#207 and \#9 showed the same behavior in both directions. The tests performed on material \#135 and \#31, in which the single fibers were easily visible, were performed with a special sample with a rectangular geometry instead of a dog-bone-shaped one. After measuring the thickness and width of a single fiber, the resistant area was computed by multiplying the area of a single fiber by the total number of fibers of each specimen.

FEM results were fully validated by the experimental data for both modeling approaches (shell and solid). The 2D analysis presented a maximum displacement (in the three-point-bending) of $41 \mathrm{~mm}$, showing a $2.5 \%$ difference with respect to the experimental data, while the 3D model predicted a maximum displacement of $44 \mathrm{~mm}$ (10\% difference vs experiments). In the torsion-bending analysis, the $2 \mathrm{D}$ model predicted a rotation of $4.60^{\circ}$, and the $3 \mathrm{D}$ model a rotation of $4.86^{\circ}$. The difference with respect to the experimental data result was $3 \%$ and $9.5 \%$, respectively.

For the shell model, discrepancies in the predicted displacement/rotation with respect to the measured one could be attributed to the following reasons:

- $\quad$ The ski was modeled with multiple sections having different heights; thus, the perfect curved shape of the ski was not correctly replicated;

- The steel edges and the lateral layers (cage) were not modeled.

On the other side, the simplification in the 3D models are:

- The longitudinal curvature of the ski was not considered;

- The assumption on the material properties taken during material characterization affected results.

Both the 2D and the 3D models had the same maximum width, but the lateral layers were modeled in the 3D model only. The second order (area) moment of these vertical layers was lower with respect to the horizontal ones; therefore, it is reasonable that the 2D models resulted in a stiffer quality compared to the 3D one. From Figure 7 to Figure 13, it can be observed that not all layers had structural purposes. The lower and the upper layers were not significantly loaded despite the maximum strain. This was due to their low elastic modulus. The material of the bottom layer, for example, was aimed to reduce friction with snow and to insulate the ski from humidity. FEA allowed for an accurate evaluation on how each layer contributed to the total stiffness of the ski.

The discrepancies observed in the torsion-bending analysis can be explained with the geometrical and material simplifications already explained, but also considering that the shear module $G$ plays a fundamental role. The fact that it was approximated with the Campbell simplification may affects results.

The simulations of the real behavior of the ski in contact with the snow showed that the rolling angle played a much more significant role with respect to the applied load in terms of turning radius. This was equal to about $22 \mathrm{~m}$ for a roll angle equal to $45^{\circ}, 34 \mathrm{~m}$ for a roll angle equal to $30^{\circ}$, and $111 \mathrm{~m}$ for a roll angle of $10^{\circ}$. The geometrical rounding radius of the ski was $40 \mathrm{~m}$. The turning radius decreased to $14 \mathrm{~m}$ when the roll angle was increased to $60^{\circ}$.

\section{Conclusions}

An accurate physical model of a real ski is a hard engineering challenge. In this paper, only a $2.5-10 \%$ error with respect to experimental data was obtained. The difficulty to properly describe the materials that composed the sandwich structure hugely influenced the model replication. The material sheets had small sizes and did not permit us to follow standards for testing their mechanical properties. The elastic module was extracted directly from the tensile tests on each material (apart from textile and the wood core, of which the properties were available in literature). DIC was used to obtain a complete material characterization. The comparison between the experimental measurements and numerical results of three-point bending and torsion-bending tests showed a satisfactory agreement. Better results were obtained with the 2D approach. The 3D model showed a higher error due to material parameter simplifications. However, theoretical predictions of the stress state and the behavior of the ski when 
subjected under bending were confirmed by an experimental test. For the torsion-bending shell model, a maximum error of 3\% was found, while for the solid one a $9.5 \%$ discrepancy was recorded. As for the bending case, the plane model presented more reliable results. This fact was due to the lower level of approximation used in the $2 \mathrm{D}$ problem.

The model was validated with experimental observations. It is now possible to easily change material properties and layer dimensions and compare different solutions in the early stages of the design phase. This can lead to a reduction of the time needed for ski development. Moreover, the need to produce several physical prototypes may no longer be necessary. As a consequence, the R\&D costs could be reduced thanks to the implemented models.

Once the model was validated, a real operating condition (interaction with the snow) was modeled. The simulation's results allowed us to quantify the stress levels in the ski together with its turning radius under different loads and roll angles. This was fundamental to optimize the equipment for a specific athlete/specific race, avoiding the massive need of expensive prototypes and experimental tests.

Author Contributions: All authors contributed actively in every part of the work. All authors have read and agreed to the published version of the manuscript.

Funding: This research received no external funding.

Acknowledgments: We would like to thank the Free University of Bolzano/Bozen for giving us the access to laboratories and for the support during the work.

Conflicts of Interest: The authors declare that they have no competing interests.

\section{References}

1. Wolfsperger, F.; Szabo, D.; Rhyner, H. Development of Alpine Skis Using FE Simulations. Proced. Eng. 2016, 147, 366-371. [CrossRef]

2. Federolf, P.; Roos, M.; Lüthi, A.; Dual, J. Finite element simulation of the ski-snow interaction of an alpine ski in a carved turn. Sports Eng. 2010, 12, 123-133. [CrossRef]

3. Zboncak, R. Experimental Verification of Ski Model for Finite Element Analysis. In Proceedings of the 56th International Conference on Experimental Stress Analysis, Harrachov, Czech Republic, 5-7 June 2018; pp. 450-456.

4. Mössner, M.; Innerhofer, G.; Schindelwig, K.; Kaps, P.; Schretter, H.; Nachbauer, W. Measurement of mechanical properties of snow for simulation of skiing. J. Glaciol. 2013, 59, 1170-1178. [CrossRef]

5. Nordt, A.A.; Springer, G.S.; Kollar, L.P. Computing the mechanical properties of alpine skis. Sports Eng. 1999, 2, 65. [CrossRef]

6. Hirano, Y.; Tada, N. Mechanics of a turning snow ski. Int. J. Mech. Sci. 1994, 36, 421-429. [CrossRef]

7. Cresseri, S.; Jommi, C. Snow as an elastic viscoplastic bonded continuum: A modelling approach. Ital. Geotech. 2005, 4, 43-58.

8. Braghin, F.; Cheli, F.; Maldifassi, S.; Melzi, S.; Sabbioni, E. The Engineering Approach to Winter Sports; Springer: New York, NY, USA, 2016.

9. Musotto, Z. Digital Image Correlation: Applicazione Di Tecniche Convenzionali E Sviluppo Di Soluzioni La Stima E L'Incremento Dell'Accuratezza. Master's Thesis, ING IV-Scuola di Ingegneria Industriale, Monteluco di Roio, Italia, 2012.

10. Crammond, G.; Boyd, S.W.; Dulieu-Barton, J.M. Speckle pattern quality assessment for digital image correlation. Opt. Lasers Eng. 2013, 51, 1368-1378. [CrossRef]

11. Makeev, A.; He, Y.; Carpentier, P.; Shonkwiler, B. A method for measurement of multiple constitutive properties for composite materials. Compos. Part A. Appl. Sci. Manuf. 2012, 43, 2199-2210. [CrossRef]

12. Kowalczyk, P. Identification of mechanical parameters of composites in tensile tests using mixed numerical-experimental method. Meas. J. Int. Meas. Confed. 2019, 135, 131-137. [CrossRef]

13. Schreier, H.W.; Sutton, M.A. Systematic Errors in Digital Image Correlation Due to Undermatched Subset Shape Functions. Exp. Mech. 2002, 42, 303-310. [CrossRef]

14. Wattrisse, B.; Chrysochoos, A.; Muracciole, J. Analysis of Strain Localization during Tensile Tests by Digital Image Correlation. Exp. Mech. 2000, 41, 29-39. [CrossRef] 
15. Peters, W. Digital image techniques in experimental stress analysis. Opt. Eng. 1982, 21, 427-431. [CrossRef]

16. Górszczyk, J.; Malicki, K.; Zych, T. Application of Digital Image Correlation (DIC) Method for Road Material Testing. Materials 2019, 12, 2349. [CrossRef] [PubMed]

17. Yokoyama, T.; Nakai, K. Evaluation of in-plane orthotopic elastic constants of paper and paperboard. Proc. SEM Ann. Conf. Expo. Exp. Appl. Mech. 2007, 3, 1505-1511.

18. Fraccaroli, L. Structural Modelling of Multilayer Skis. M.Sc. Thesis, Free University of Bozen-Bolzano, Bolzano, Italy, 2019.

19. Lintzén, N.; Edeskär, T. Uniaxial strength and deformation properties of machine-made snow. J. Cold Reg. Eng. 2015, 29, 04014020. [CrossRef]

20. GOM. Available online: www.gom.com (accessed on 1 May 2020).

21. Tecnologie E Materiali Aerospaziali. CAPITOLO 32-Materiali Compositi: La Legge Costitutiva Ortotropa. Available online: Https://www.andreadd.it/appunti/polimi/ingegneria/corsi/en_mec_aes/ing_aerospaziale/ anno3/TecnologieMaterialiAerospaziali/viewer.html?file=appunti/Teoria_Riassunto.pdf (accessed on 1 May 2020).

(C) 2020 by the authors. Licensee MDPI, Basel, Switzerland. This article is an open access article distributed under the terms and conditions of the Creative Commons Attribution (CC BY) license (http://creativecommons.org/licenses/by/4.0/). 